\title{
Dilemmas associated with antenatally detected urinary tract abnormalities
}

\author{
A R WATSON, ${ }^{*}$ D READETT, ${ }^{*}$ C S NELSON, $\dagger$ L KAPILA, $\neq$ AND M J MAYELL $*$ \\ *City and $\ddagger$ University Hospitals, Nottingham, and †Derbyshire Children’s Hospital, Derby
}

SUMMARY Over a five year period 55 fetuses had abnormalities of the urinary tract detected by antenatal ultrasound scan. The incidence was 1:935 total births during a one year prospective study. Intrauterine intervention was undertaken in five for suspected obstructive uropathy, which was confirmed in only two. Of 51 live born infants, five died (two with renal failure), and only 18 $(35 \%)$ had a clinically detectable abnormality at birth. Twenty seven patients underwent postnatal operations, the remainder being treated conservatively.

Antenatal counselling was seldom undertaken by those responsible for the postnatal care. There were many instances of prospective parents receiving little or inappropriate information. Greater cooperation is required between all the staff concerned particularly as the natural history and appropriate postnatal management of some urinary tract abnormalities are still not known.

The use of real time ultrasonography in obstetric practice has resulted in an increase in the detection rate of fetal urinary tract abnormalities in district hospitals as well as in specialist centres. ${ }^{2}$ Any suggestion of fetal abnormality on the antenatal scan can cause great anxiety and distress to the parents. ${ }^{3}$ Abnormalities can, however, be difficult to characterise fully given the limitations of ultrasonography and the relative paucity of knowledge about the natural history of developmental lesions. ${ }^{+}$Previous reports have documented a poor correlation between the antenatal findings and the postnatal diagnoses. 56

Problems of diagnostic accuracy are combined with uncertainty about both the prognosis of many of the abnormalities and of the role of prenatal surgery. ${ }^{78}$ Urinary tract abnormalities occur in about 1:1200 pregnancies" and hence the individual members of the obstetric and paediatric staff are likely to have only limited experience with these lesions. Poor communication among staff in different specialities will only add to the difficulties of counselling the parents both antenatally and postnatally. We report our experience to illustrate some of the diagnostic and therapeutic dilemmas that arise when urinary tract abnormalities are detected antenatally. We emphasise the need for good communication and exchange of information among staff in the departments of obstetrics, radiology, and paediatrics.

\section{Patients and methods}

Between January 1982 and December 1986, 55 cases of antenatally diagnosed urinary tract abnormalities came to our attention either by referral for postnatal management, notification by the perinatal pathologist, or (latterly) referral for antenatal counselling. The number of cases increased from five in 19,82 to 21 in 1986 . The data were collected prospectively during 1986 and included fetal urinary tract abnormalities that resulted in termination of pregnancy or intrauterine fetal death.

It is the policy in all the referring centres to perform a routine ultrasound scan between 16 and 20 weeks' gestation. Further ultrasound examinations were for obstetric reasons except in one Nottingham centre where serial ultrasound scans were routinely carried out between 28 and 34 weeks as part of a research project into fetal growth. The ultrasound scans were performed by trained radiographers who called in a radiologist for more detailed scanning if an abnormality was detected or strongly suspectedfor example, if oligohydramnios was seen.

Five mothers were referred to a specialist centre where antenatal bladder drainage procedures were 
performed. These comprised insertion of an intrauterine vesicoamniotic shunt in three fetuses, and bladder aspiration in two (table 1).

\section{Results}

The gestational age of detection of the urinary tract abnormality ranged from 18 to 39 weeks with a mean of 32 weeks (mode 32 weeks). Forty one of the 55 fetuses were male and 14 female. In most instances the antenatal scan had been reported as showing hydronephrosis or cystic areas in the kidney(s), with few specific diagnoses. Infantile polycystic kidneys had been suggested inappropriately on two occasions.

During a prospective study of the 10291 births in Nottingham in 1986, 11 urinary tract abnormalities were found, an incidence of 1.07 per thousand. Three pregnancies were reported as showing mild hydronephrosis in one or both fetal kidneys on scans late in pregnancy but these were not confirmed on subsequent antenatal or postnatal scans.

Five fetuses were thought to have obstructive uropathy (posterior urethral valves) from the ultra- sound findings, and underwent intrauterine operation (table 1). Only two of the five were subsequently proved to have urethral valves at necropsy and both died before 22 weeks' gestation. The other three infants had non-obstructive uropathy with megalocystis megaloureter in two (one with prune belly syndrome), and bilateral vesicoureteric reflux in the other. All three are alive but one has chronic renal failure due to associated dysplastic kidneys.

Of the 55 fetuses, 51 were born alive. In addition to the two fetuses with posterior urethral valves (table 1), one pregnancy was terminated at 19 weeks because of oligohydramnios (the kidneys were normal at necropsy), and one fetus was stillborn at 34 weeks' gestation with Potter's syndrome.

Five of the 51 infants born alive subsequently died (table 2). Two died of renal failure at 4 hours and 14 days, with bilateral multicystic kidneys and posterior urethral valves, respectively. One infant died at 3 days of a pulmonary embolus unrelated to the renal problem of bilateral obstruction of the pelviureteric junctions. One died of a hypoplastic left heart, and one of a ventricular septal defect together with trisomy 18 syndrome and a persistent urachus.

Table 1 Details of intrauterine operations in five patients

\begin{tabular}{|c|c|c|c|c|}
\hline $\begin{array}{l}\text { Gestational age } \\
\text { at detection } \\
\text { (weeks) }\end{array}$ & $\begin{array}{l}\text { (jestational age } \\
\text { at operation } \\
\text { (weeks) }\end{array}$ & $\begin{array}{l}\text { Intratuterine } \\
\text { operation }\end{array}$ & Postmatal diagnosis & Outcome \\
\hline 19 & 20 & Vesicoamniotic shunt & Posterior urethral values & $\begin{array}{l}\text { Termination of pregnancy } \\
\text { at } 21 \text { wecks gestation } \\
\text { Deletion long arm } \\
\text { chromosome } 2\end{array}$ \\
\hline 20 & 21 & Vesicoamniotic shunt & Posterior urethral valves & $\begin{array}{l}\text { Intrauterine fetal death at } \\
22 \text { wecks gestation }\end{array}$ \\
\hline 18 & 20.30 .31 & $\begin{array}{c}\text { Bladder drainage } \\
\text { by aspiration }\end{array}$ & Megalocystis. megaloureters & Alive and well \\
\hline 33 & 33 & $\begin{array}{l}\text { Bladder drainage } \\
\text { by aspiration }\end{array}$ & $\begin{array}{l}\text { Bilateral vesicoureteric reflux } \\
\text { (left worse than right) }\end{array}$ & Alive and well \\
\hline
\end{tabular}

*Prune belly syndrome.

Table 2 Diagnosis and outcome in 51 infants born alive

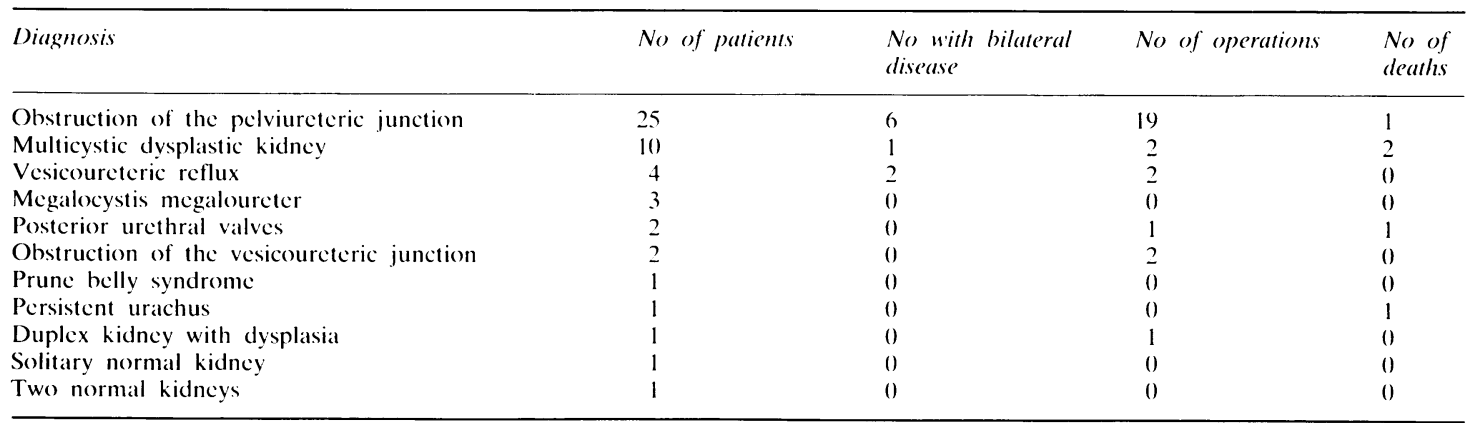


There were two other infants who also had chromosomal abnormalities. The infant with Turner's syndrome and obstruction to the left pelviureteric junction survived, but termination of pregnancy was carried out for the fetus with deletion of the long arm of chromosome 2 and posterior urethral valves.

Only $18(35 \%)$ of the problems were clinically apparent at birth. All patients were initially investigated by ultrasonography in the neonatal period, and subsequently $34(67 \%)$ had micturating cystourethrograms; $25(49 \%){ }^{99 m}$ technetium diethylenetriamine penta-acetic acid renal scans; 20 (39\%) intravenous urograms and six $(12 \%){ }^{99 \mathrm{~m}}$ technetium dimercaptosuccinic acid scans.

Of the 51 infants born alive 27 had been operated on at the time of writing. Eighteen patients had had pyeloplasties; four had reimplantation of the ureters, four had nephrectomies (one heminephrectomy), and one patient had diathermy of the posterior urethral valves. The remaining 24 are being managed conservatively and some may require operation later.

\section{Discussion}

The present series documents an incidence of antenatally detectable urinary tract abnormalities of 1:935 pregnancies. This compares with the 1:1200 incidence quoted by Kullendorff $e t$ al in a 24 month prospective screening programme in Lund, ${ }^{9}$ and the incidence of approximately 1:333 reported from Malmo. ${ }^{10}$ Although the latter study detected 33 abnormalities in 11986 pregnancies over five years with routine scanning at 17 and 33 weeks' gestation there were 10 cases of hydroureter, hydronephrosis, or solitary cyst that extensive postnatal investigation showed to be only mild dilatation of the ureters or renal pelvis, or both, with no definitive diagnosis.

During our prospective study in 1986 three instances of transient dilatation of the fetal renal pelvis were noted. Such transient dilation is not uncommon in the first half of pregnancy but its recognition later on does raise the dilemma of how far to investigate postnatally if the follow up ultrasound scan is normal. Smith et al recognised two infants with mild hydronephrosis in utero who had normal postnatal scans and were discharged from follow up. Both were subsequently shown to have vesicoureteric reflux when investigated later, one for urinary tract infection and one for septicaemia. $^{1}$

The diagnostic accuracy of the antenatal ultrasound scans did seem to improve during the study and this probably reflects improvement in the technical field as well as the learning curve of the ultrasound operators. Though Pocock et al sug- gested that the antenatal ultrasound examination correctly diagnosed the urological abnormality in all but four of 28 patients, the ultrasound diagnosis was often non-specific, as in our series, and consisted largely of hydronephrosis or cystic appearances in both kidneys. " Of some concern are the instances of incorrect diagnoses being made-for example, infantile polycystic kidneys. The prognosis for this condition may be poor, and one set of parents in our series were counselled inappropriately because the fetus was subsequently shown to have apparently normal kidneys. Another infant had severe bilateral vesicoureteric reflux.

Because only $35 \%$ of urinary tract abnormalities were clinically detectable at birth there have been many management dilemmas posed by the detection of problems that might have remained clinically silent. The need for removal of an asymptomatic multicystic dysplastic kidney and the timing of operation for obstruction to the pelviureteric junction are two such examples. 121.3

More important is the place of antenatal surgical intervention. ${ }^{814} 15$ The fetus with a unilateral renal lesion can safely be observed if a normal kidney is present on the other side and there is no evidence of oligohydramnios. The dilemma arises if the fetus has both kidneys affected. In a highly selected series of 73 placements of catheter shunts for fetal obstructive uropathy reported to the International Fetal Surgery Registry, the death rate associated with the operation was $4 \cdot 6 \% .{ }^{16}$ The procedure was undertaken at a mean (SD) of $24 \cdot 2$ (5) weeks (range 17 to 36$)$ and 30 fetuses $(41 \%)$ survived. Twenty seven of the 29 postnatal deaths were due to pulmonary hypoplasia, and of the 30 surviving fetuses, 16 had posterior urethral valves, one had urethral atresia, three had prune belly syndrome, and 10 died of unknown causes. The reasons for selection and lack of details about the patients makes interpretation of any possible benefit difficult.

Our own series highlights the problem of differentiating true obstructive uropathy from nonobstructive lesions, and we further question the role of untrauterine intervention. The fetus with bilateral renal disease associated with oligohydramnios early in pregnancy seems to have a poor prognosis with a high incidence of chromosomal abnormalities. ${ }^{2}$ Most urinary tract abnormalities, however, will be recognised on a scan later in the pregnancy. In the rare instance of a fetus developing increasing bilateral hydronephrosis from suspected obstructive uropathy, early delivery in an appropriate neonatal unit may be preferable to antenatal operation.

Reviewing our experience has led us to assess critically the lines of communication that are used 
when an abnormality is detected antenatally. A report of such an abnormality by the radiographer to the referring obstetrician may result in a request to a radiologist for a repeat scan, referral of the patient to a specialist obstetrics centre, enlistment of the help of a paediatric physician or surgeon, or a "wait and see' policy. Counselling is generally done by the obstetricians. Though we do not have accurate information about the timing or content of parental counselling we do know of many instances of inappropriate counselling, and also of parents not being told of abnormalities before the birth of their child. In most instances the paediatric staff were not informed before the birth of the child either, and this has also been reported from other centres. It is obvious that there should be greater interchange of information among staff in the departments of obstetrics, radiology, paediatrics, and clinical genetics. All parents that we have spoken to have suggested that more information would have been welcome and the sharing of knowledge among the disciplines can only help us all to traverse the learning curve. Discussion of our own local experience with our obstetric colleagues has led to more requests for antenatal counselling by the paediatric staff.

We thank Drs J Minford. J Zuccollo, and D Fagan for information about patients, and Rachel Horn for typing the manuscript.

\section{References}

' Smith D, Egginton JA. Brookficld DSK. Detection of abnormality of fetal urinary tract as a predictor of renal tract disease. Br Med J 1987:294:27-8.
2 Nicolaides KH. Rodeck CH. Gesden CM. Rapid karyotyping in non-lethal fetal malformations. Lancel 1986:i:284-7.

Furness ME. Reporting obstetric ultrasound. Lancet 1987: i: $675-6$.

+ Thomas DFM. Urological diagnosis in utero. Arch Dis Child 1984:59:913-5.

s Turnock RR. Shawis R. Management of fetal urinary tract anomalies detected by prenatal ultrasonography. Arch Dis Child 1984:59:962-5.

"Avni EF. Rodesch F. Schulman CC. Fetal uropathies: diagnostic pitfalls and management. J Urol 1985;134:921-5.

7 Broyer M. Guest G. Lestage F. Gacoin FE. Prenatal diagnosis of urinary tract malformations. Adv Nephrol 1985:14:21-38

" Nicolaides Kh. Rodeck CH. Fetal therapy. In: Strudd J. ed. Progress in obstetrics and gynaecology 5. Edinburgh: Churchill Livingstone, 1985:36-57.

"Kullendorff CM, Larsson LT, Jorgensen C. The advantage of antenatal diagnosis of intestinal and urinary tract malformations. Br J Obstet Gynaecol 1984:91:144-7.

11 Helin I. Persson P-H. Prenatal diagnosis of urinary tract abnormalities by ultrasound. Pediatrics 1986:78:879-83.

11 Pocock RD. Witcombe JB. Andrews HS. Berry PJ, Frank JD. The outcome of antenatally diagnosed urological abnormalities. Br J Urol 1985:57:788-92.

12 Maizels M. Wacksman J, Belman AB, Colodny AH. Management of multicystic dysplastic kidney. Dialogues in Pediatric Urology 1987:10:1-8.

1.3 Homsy YL. Williot P. Danais S. Transitional neonatal hydronephrosis: Fact of fantasy? J Urol 1986;136:339-41.

${ }^{14}$ Kramer SA. Current status of fetal intervention for congenital hydronephrosis. J Urol 1983;130:641-6.

is Glick PL, Harrison MR, Adzick NS, Noall RA. Villa RL. Correction of congenital hydronephrosis in utero IV: in utero decompression prevents renal dysplasia. J Pediatr Surg 1984;19: 649-57.

16 Manning FA. Harrison MR, Rodeck C. Catheter shunts for fetal hydronephrosis and hydrocephalus. Report of the International Fetal Surgery Registry N Engl J Med 1986;315:336-40.

Correspondence and requests for reprints to Dr Alan R Watson. Paediatric Renal Unit, City Hospital. Nottingham NG5 IPB.

Accepted 13 January 1988 